\title{
APLICAÇÃO DO MÉTODO DE POLARIZAÇÃO INDUZIDA EM ÁREA DE DISPOSIÇÃO DE RESÍDUOS SÓLIDOS NO MUNICÍPIO DE CAÇAPAVA DO SUL - RS
}

\author{
Mônica Teixeira de Oliveira ${ }^{1}$ César Augusto Moreira² e Aline Muriel da Cunha Menezes³ \\ Recebido em 14 setembro, 2010 / Aceito em 3 dezembro, 2010 \\ Received on September 14, 2010 / Accepted on December 3, 2010
}

\begin{abstract}
The geophysics is an effective method for investigation of contaminated areas for the most several types of pollutants, mainly in areas of disposition of residues solid, used in the characterization of contrasts of physical properties in the presence of pollutant substances. This work applies the Polarization Induced method in waste landfill, located in Caçapava do Sul city (RS). The landfill this seated on fractured metamorphic rocks, belonging to the Vacacaí Metamorphic Complex (Neoproterozoic). Were accomplished 8 lines of electric profiling, with spacing of $5 \mathrm{~m}$ between electrodes and 10 investigation levels. Were also accomplished 83 measures of strike and dip fractures. The geophysical result allows characterize the layer of residues for low chargeability values. Vertical anomalies below the layer of residues are interpreted as fracture zones with possible leachate accumulation, characterized by low chargeability values.
\end{abstract}

Keywords: leachate, waste, fracture, chargeability.

RESUMO. A geofísica é um método eficaz para investigação de áreas impactadas pelos mais diversos tipos de contaminantes, principalmente em locais de disposição de resíduos sólidos domiciliares e também utilizada na caracterização de contrastes de propriedades físicas em presença de substâncias poluentes. Este trabalho utilizou o método de Polarização Induzida numa área de disposição de resíduos sólidos desativada, localizada no município de Caçapava do Sul - RS. 0 aterro está assentado sobre rochas metamórficas fraturadas, pertencentes ao Complexo Metamórfico Vacacaí (Neoproterozóico). Foram realizadas 8 linhas de caminhamento elétrico, com espaçamento de $5 \mathrm{~m}$ entre eletrodos e 10 níveis de investigação, além de 83 medidas de direção e sentido de fraturas. 0 resultado geofísico permite caracterizar a camada de resíduos por baixos valores de cargabilidade. Anomalias verticais abaixo da camada de resíduos são interpretadas como zonas de fratura com possível acúmulo de chorume, caracterizadas por baixos valores de cargabilidade.

Palavras-chave: chorume, lixo, fraturas, cargabilidade.

\footnotetext{
${ }^{1}$ Graduação em Geofísica, Universidade Federal do Pampa - UNIPAMPA, Campus de Caçapava do Sul, RS, Brasil - E-mail: monyckaolyveira@hotmail.com

2 Departamento de Geologia Aplicada (DGA), Universidade Estadual Paulista - UNESP, Av. 24A, 1515, Bela Vista, Caixa Postal 179, 13506-900 Rio Claro, SP, Brasil. Tel./Fax: (19) 3526-9313 - E-mail: moreirac@rc.unesp.br

3 Graduação em Geofísica, Universidade Federal do Pampa - UNIPAMPA, Campus de Caçapava do Sul, RS, Brasil - E-mail: alinedacunhs@gmail.com
} 


\section{INTRODUÇÃo}

A disposição incorreta ou o manuseio indevido de resíduos sólidos geram sérios problemas para 0 ambiente, inclusive com grande impacto nas águas subterrâneas. Aterros bem construídos (impermeabilizados e com drenos de coleta de lixiviados), operados com eficiência (com cobertura de solo ao final de cada período de serviço) e em localização correta (onde a vulnerabilidade do aquífero subjacente não tenha índices altos) são alternativas seguras para muitos resíduos, mas não para todos.

Vários estudos de poluição das águas subterrâneas demonstram que todo lixão ou aterro controlado provoca algum tipo de poluição. Assim, preocupações como a contaminação do solo e dos recursos hídricos, das plantas, dos animais e do homem, decorrente da presença de elementos metálicos provenientes da inadequada disposição de resíduos sólidos, conduzem pesquisadores a direcionar seus objetivos de pesquisa a estes problemas (Oliveira \& Pasqual, 2004).

0 gerenciamento de resíduos sólidos urbanos tem sido um verdadeiro desafio aos gestores públicos, devido a problemas como áreas disponíveis, licenciamento ambiental, custos de transporte, dentre outros. Segundo Pesquisa Nacional de Saneamento Básico (IBGE, 2002), a situação atual dos municípios brasileiros referente à disposição final dos resíduos sólidos urbanos é: 37,0\% dos resíduos sólidos são depositados em aterros sanitários, 36,1\% são depositados em aterros controlados, 22,5\% em vazadouro a céu aberto (lixão), 2,9\% em estação de compostagem, 1,0\% em estação de triagem, e 0,5\% incinerados (Jucá, 2003).

A omissão dos órgãos de fiscalização ou o simples descaso da população, muitas vezes resultam no descarte clandestino de resíduos, geralmente em áreas inapropriadas, como nascentes, rios e áreas de proteção permanente. Caso o solo sob os resíduos seja permeável e desprotegido, o chorume pode atingir o nível freático. A geração de chorume pode ultrapassar quinze anos após o final da deposição de lixo, dependendo de vários fatores (Possamai et al., 2007).

Atualmente os métodos geofísicos têm sido amplamente utilizados neste tipo de estudo devido à sua rapidez e custo relativamente baixo quando comparados a outras técnicas de investigação. Os principais métodos geofísicos para investigação de contaminantes são: Eletromagnéticos, Eletrorresistividade, Potencial Espontâneo, Radar de Penetração no Solo e eventualmente Magnetometria (CETESB, 2001).

0 trabalho de Moreira \& Braga (2009) apresenta os resultados de aplicação da Eletrorresistividade e Polarização Induzida, na análise da área de percolação de chorume proveniente de aterro de resíduos sólidos dispostos em valas com datas de fechamento programado. A profundidade do nível freático da área é de $45 \mathrm{~m}$. Os resultados sugerem uma associação entre anomalias de alta cargabilidade em valas de resíduos fechadas recentemente, enquanto que as anomalias de baixa resistividade independem da idade de fechamento das valas. As áreas com alta cargabilidade provavelmente estão relacionadas à precipitação de Ferro, dissolvido por ataque do chorume no solo e nos materiais metálicos presentes nos resíduos.

Numa área do aterro controlado da cidade de Rio ClaroSP, Moura \& Malagutti (2003) realizaram ensaios geofísicos, pelos métodos da Eletrorresistividade e Polarização Induzida, por meio das técnicas de sondagem elétrica vertical e caminhamento elétrico, com o objetivo de avaliar as potencialidades da integração dos métodos na caracterização geoelétrica da área. A geologia sobre a qual está assentado o aterro é constituída por sedimentos cenozóicos assentados discordantemente sobre siltitos e argilitos da Formação Corumbataí. A interpretação conjunta da resistividade e da polarizabilidade, além de reduzir a ambiguidade dos modelos geoelétricos unidimensionais e bidimensionais interpretados, permitiu determinar a geometria das cavas de resíduos, zonas de percolação de chorume e identificar os diferentes litotipos. Neste trabalho, ficou evidente que a polarizabilidade é sensivel à presença de resíduos urbanos, e que 0 efeito IP é relacionado a materiais polarizáveis dispostos na cava, como latas, papéis, restos eletrônicos e materiais de empréstimo utilizados para a cobertura dos resíduos.

0 estudo de Lago et al. (2006) teve como finalidade avaliar as potencialidades da integração dos métodos geofísicos (Eletrorresistividade, Polarização Induzida e Potencial Espontâneo) na caracterização geoambiental da área do aterro sanitário da cidade de Bauru-SP. 0 resultado do Potencial Espontâneo possibilitou detectar o sentido do fluxo subterrâneo. Os métodos de Eletrorresistividade e Polarização Induzida permitiram identificar anomalias dentro da zona saturada, que caracterizaram a presença da contaminação gerada pela migração do percolado proveniente da disposição dos resíduos sólidos. A contaminação é confirmada por investigação direta (análise química da água coletada nos poços de monitoramento). Os métodos geofísicos utilizados forneceram um grande número de informações sobre as diversas características relacionadas à interação entre a área de disposição de resíduos sólidos urbanos e o meio físico. Com a utilização conjunta desses métodos foi possível ainda orientar a locação de ensaios por métodos diretos de investigação, assim como a locação adequada de poços de monitoramento na área. 


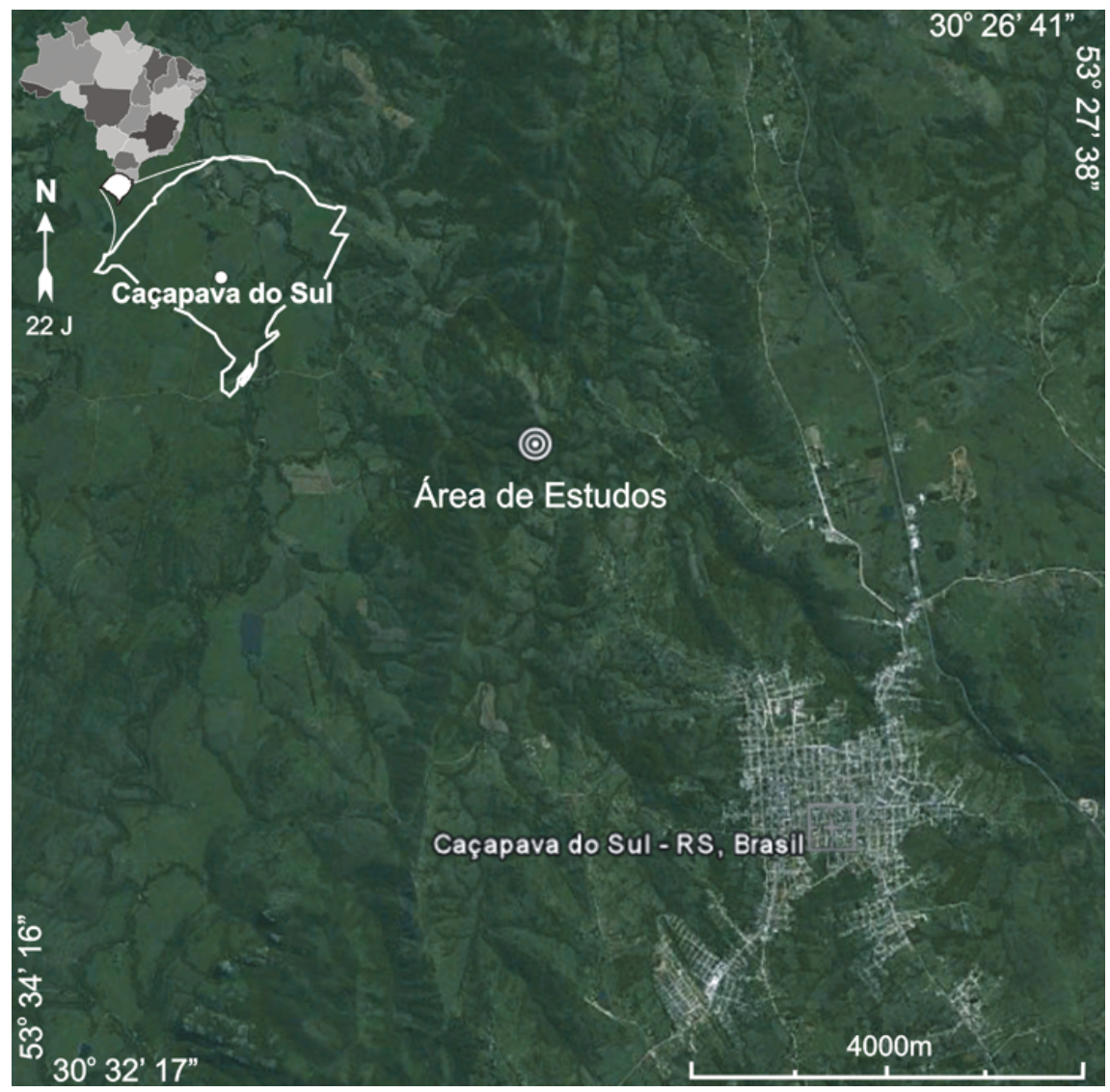

Figura 1 - Localização da área de estudos (Adaptado de Google Earth, 2010).

0 presente trabalho visa realizar uma investigação geofísica por meio do método de Polarização Induzida numa área de disposição de resíduos sólidos domiciliares, assentado sobre rochas fraturadas, no município de Caçapava do Sul. Os objetivos são a definição da espessura de resíduos enterrados e a presença de caminhos preferenciais de fluxo associado ao fraturamento do substrato, avaliação do comportamento dos parâmetros físicos medidos em relação aos resíduos enterrados e o líquido proveniente da degradação de resíduos orgânicos.

\section{CARACTERIZAÇÃO DA ÁREA DE ESTUDOS}

A área de estudos foi um local de disposição de resíduos sólidos domiciliares, localizado no Rincão dos Bitencourt, zona rural do município de Caçapava do Sul - RS (Fig. 1).

0 município possui cerca de 33.060 habitantes (IBGE, 2009) com produção diária atual próxima de 12 toneladas de lixo doméstico. A área de estudos foi utilizada durante 14 anos, entre 1980 e 1994. Durante esse período o lixão recebeu em torno de 28.000 toneladas de material, depositado a céu aberto, causando poluição ao meio ambiente.
Esta área é limitada a Norte e a Sul por duas drenagens, que configuram um nível freático bastante raso. A drenagem Sul apresenta elevação de $192 \mathrm{~m}$ acima do nível do mar, enquanto que a drenagem Norte possui elevação de 178 m, ambas separadas por uma distância de $155 \mathrm{~m}$. 0 gradiente hidráulico estimado é de $5,15^{\circ}$ para Norte ao longo da vala.

Durante seu período de funcionamento, houve significa poluição destas águas, pois não havia quaisquer sistemas de coleta e armazenamento de chorume (PMC, 1996).

0 contexto geológico da área compreende rochas do Complexo Metamórfico Vacacaí, constituído por uma unidade vulcânica e uma unidade vulcano-sedimentar (CPRM, 2008). Este complexo é limitado principalmente por coberturas vulcanosedimentares não metamórficas e intrudida por granitos sintranscorrentes, tardi- a pós-tectônicos.

A área de estudos está assentada sobre a unidade vulcanosedimentar, que ocorre em uma faixa de orientação variável entre N-S e NE-SW, com início a Norte da Suíte Granítica Caçapava do Sul até 0 extremo-Sul da Folha Cachoeira do Sul (CPRM, 2000). Por sua vez, Bitencourt (1983) caracterizou dois even- 


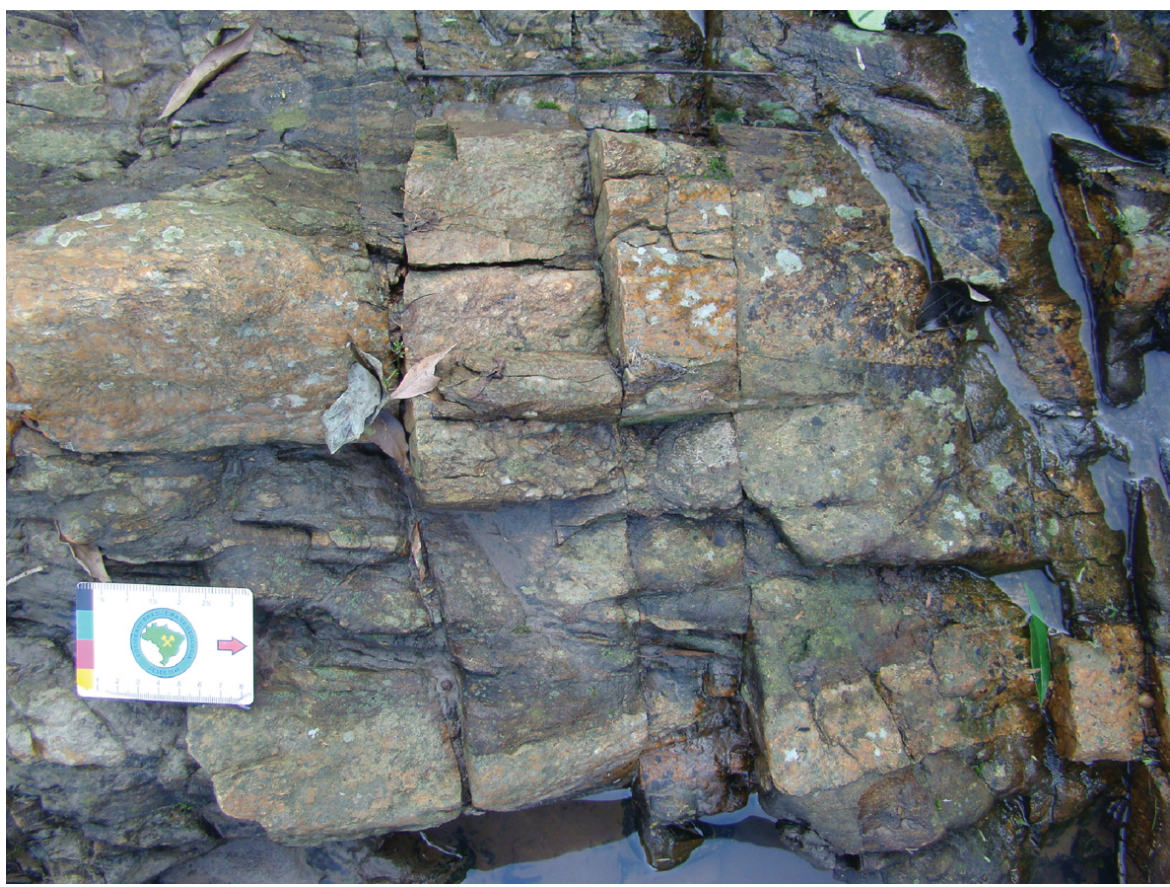

Figura 2 - Mica xisto fraturado, posicionado no início da linha 4, a sul da área do aterro.

tos metamórficos regionais, dos quais o mais antigo é representado por paragêneses compatíveis com a fácies anfibolito; 0 segundo evento, relacionado à fase de deformação responsável pela xistosidade regional, é essencialmente retrogressivo e apresenta associações mineralógicas compatíveis com a fácies xisto verde.

A Suíte Granítica Caçapava do Sul compreende dois corpos graníticos intrusivos no Complexo Metamórfico Vacacaí. 0 corpo maior possui uma forma ovalada cujo eixo maior, com cerca de 25 km de extensão, está orientado segundo uma direção N-S e denomina a suíte. Esta suíte é constituída dominantemente de monzo e sienogranitos com participação subordinada de rochas de composição granodiorítica a tonalítica (CPRM, 2000).

0 Complexo Metamórfico Vacacaí é localmente caracterizado por anfibolitos, mica-xisto e talco-xisto (Fig. 2).

\section{MÉTODO}

0 método de Polarização Induzida é baseado na medição das variações de voltagem em função do tempo ou frequência (Telford et al., 1990). Este trabalho utiliza a medida de Polarização Induzida no domínio do tempo. 0 parâmetro físico medido é a cargabilidade, neste caso é medido em mVN.

A cargabilidade é definida como (Eq. 1):

$$
M=\frac{1}{V_{c}} \int_{t_{1}}^{t_{2}} V(t) d t
$$

Este trabalho adota a técnica de caminhamento elétrico, que consiste numa investigação 2D com movimentação lateral dos eletrodos de transmissão e recepção e investigação em vários níveis de profundidade (Lowrie, 2007). 0 presente trabalho aplica 0 arranjo de campo dipolo-dipolo, que consiste em dois polos de leitura de corrente e dois polos de leitura de potencial, 0 espaçamento entre os eletrodos de corrente e potencial é constante (Milsom, 2003).

Foi utilizado o resistivímetro SYSCAL PRO, fornecido pela Universidade Federal do Pampa (UNIPAMPA). Este equipamento realiza leituras de resistividade elétrica, cargabilidade elétrica e voltagem, possui $250 \mathrm{~W}$ de potência e 2,5A de corrente. Foram utilizados eletrodos não polarizáveis a base de uma solução salina de sulfato de cobre $\left(\mathrm{CuSO}_{4}\right)$. Esta solução consiste em água, na qual é adicionado $\mathrm{CuSO}_{4}$ granulado, até a saturação ser atingida. Os dados foram processados no programa RES2DINV (Loke \& Barker, 1996).

\section{RESULTADOS}

Para a aquisição de dados foram realizadas 8 linhas de caminhamento, com espaçamento de $5 \mathrm{~m}$ entre eletrodos e $10 \mathrm{~m}$ de separação entre linhas.

As linhas seguem a direção N-S, com início na porção Sul da área e final na porção Norte, topograficamente mais baixa (Fig. 3). 
A linha 8 foi realizada no limite do aterro, numa vala posicionada na porção topográfica mais baixa da área. Esta vala foi aberta com a finalidade de canalizar o fluxo de águas superficiais, além de possivelmente direcionar também o fluxo subterrâneo (Fig. 3).

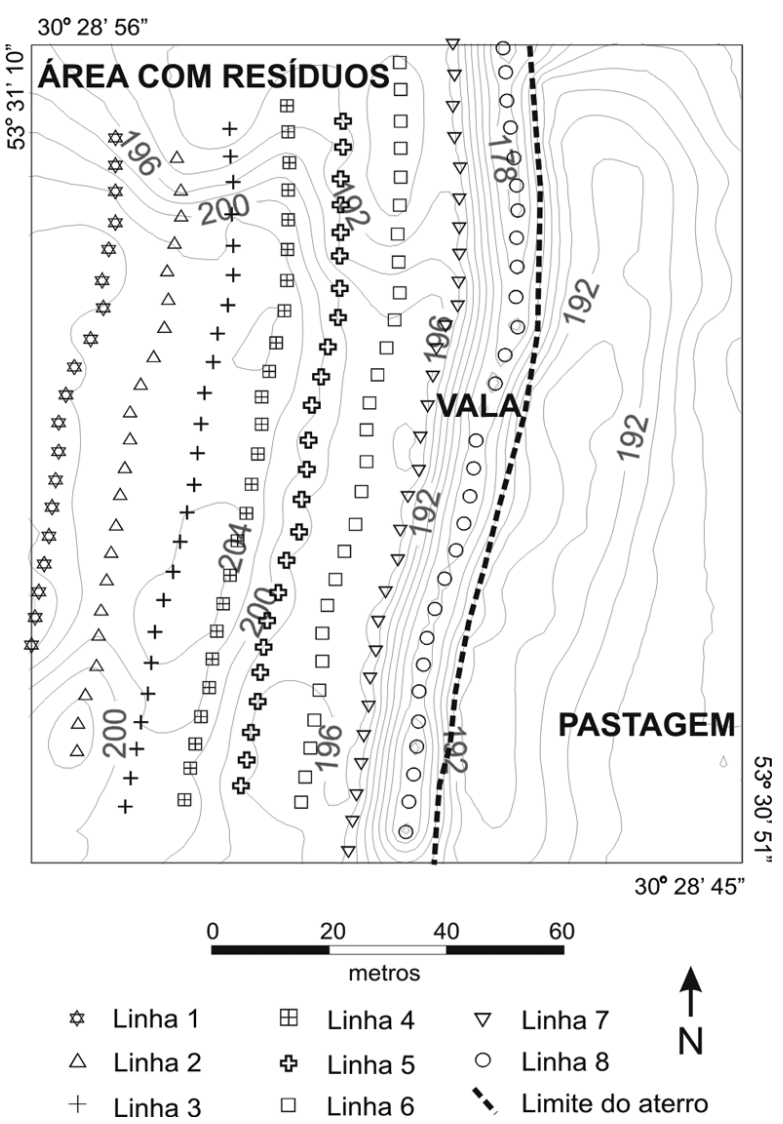

Figura 3 - Linhas de caminhamento elétrico e topografia da área.

Foram realizadas 83 medidas de direção e sentido de fraturas, em exposições de rochas aflorantes no início e no final das linhas de caminhamento. Os dados estruturais estão representados na forma de estereograma (Fig. 4).

0 diagrama indica o predomínio de direções de fraturas entre $\mathrm{N} 90^{\circ}$ a $\mathrm{N} 110^{\circ}$ e mergulho de $90^{\circ}$. Este fato induziu a programação das linhas de caminhamento de forma perpendicular à estruturação geral da área.

As linhas de caminhamento elétricos 1 a 7 foram realizadas sobre as áreas de resíduos enterrados, com a linha 8 realizada no limite do aterro (Fig. 3). A partir deste ponto serão discutidos os modelos de inversão destas linhas (Figs. 5 e 6).

Todas as linhas apresentam anomalias verticais de baixa cargabilidade no intervalo da rocha, localizada a $60 \mathrm{~m}$ e $120 \mathrm{~m}$ do início das linhas, valores entre $1 \mathrm{mV} / \mathrm{N}$ e $18 \mathrm{mV} / \mathrm{N}$, que provavelmente refletem a percolação de chorume em fraturas.

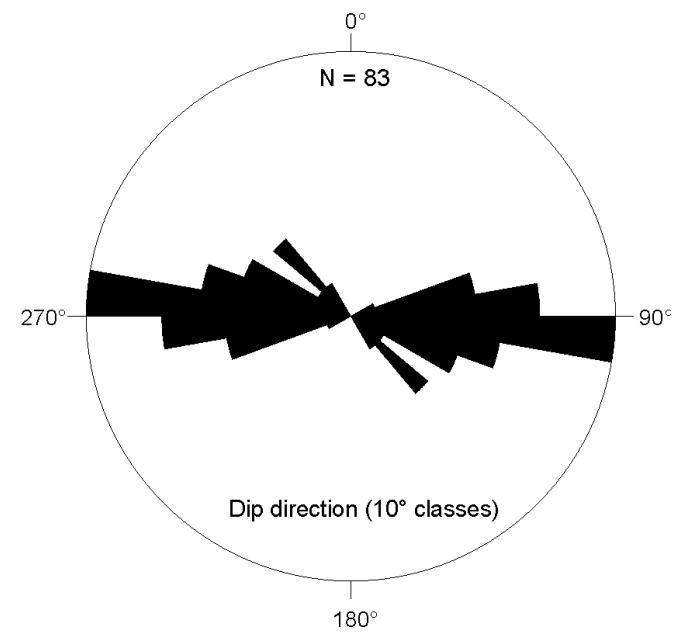

Figura 4 - Estereograma com medidas de fraturas.

Com base nas informações de campo referentes à espessura de resíduos em diversos pontos da área é possível afirmar que nas seções modeladas a faixa de valores entre $1 \mathrm{mV} / \mathrm{V}$ e $20 \mathrm{mV} / \mathrm{V}$ define 0 intervalo desde a superfície até a base da camada de resíduos, que correspondem à profundidade de $6 \mathrm{~m}$ a $8 \mathrm{~m}$, e que valores superiores a $20 \mathrm{mV} / \mathrm{N}$ definem os anfibolitos e xistos presentes na região estudada (Figs. 5 e 6).

Em campo foi comprovado que a espessura de lixo aumenta gradativamente de Oeste para Leste. As seções corroboram este fato, pois há 0 aumento da espessura da faixa de baixos valores de cargabilidade também neste sentido (Figs. 5 e 6 ).

A linha 8 foi realizada no limite do aterro e apresenta valores entre $12 \mathrm{mV} / \mathrm{N}$ e $26 \mathrm{mV} / \mathrm{N}$ para 0 intervalo correspondente à camada de resíduos. Esta linha apresenta valores mais elevados quando comparados as seções anteriores. A área cruzada por esta linha não apresenta resíduos enterrados, em contraste com as demais linhas, que cruzam a camada de resíduos enterrados (Fig. 6).

As linhas 1 e 7 apresentam um padrão semelhante ao descrito para a linha 8, possivelmente devido à pequena espessura de resíduos na área cruzada por esta linha.

\section{DISCUSSÃO E CONCLUSÕES}

Os resultados deste trabalho permitem caracterizar a camada de resíduos sólidos por baixos valores de cargabilidade (abaixo de $20 \mathrm{mV} / \mathrm{N}$ ), numa condição de nível freático raso definido pelo contato solo/rocha, que corresponde à base da camada de resíduos.

0 trabalho de Lago et al. (2006) descreve uma faixa ampla de valores de cargabilidade (entre 0,1 mV/ e $26 \mathrm{mV} / \mathrm{N}$ ) em valas com resíduos enterrados num contexto de zona insaturada, ou seja, acima do nível freático. 0 trabalho de Moura \& Malagutti 


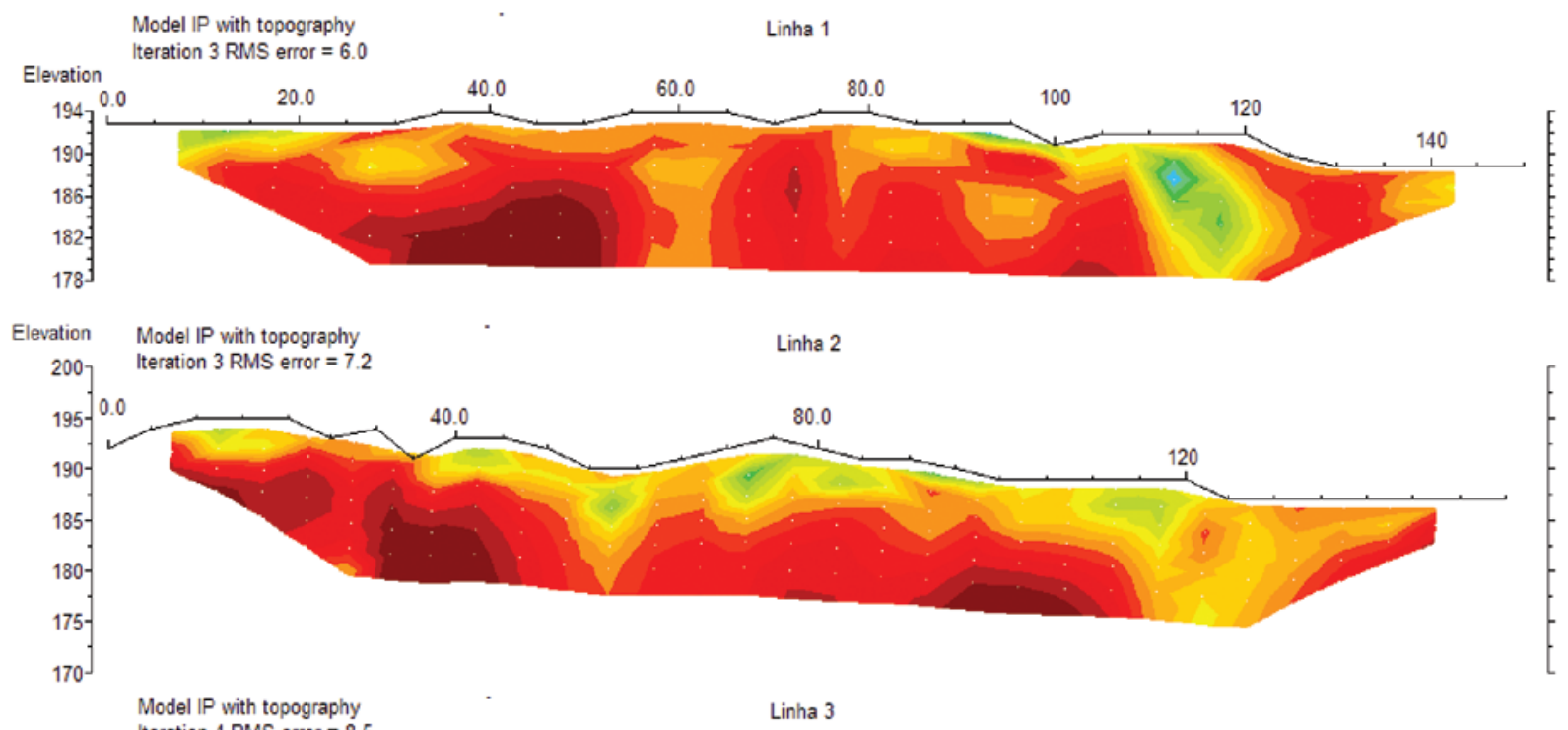

Elevation Iteration 4 RMS error $=8.5$

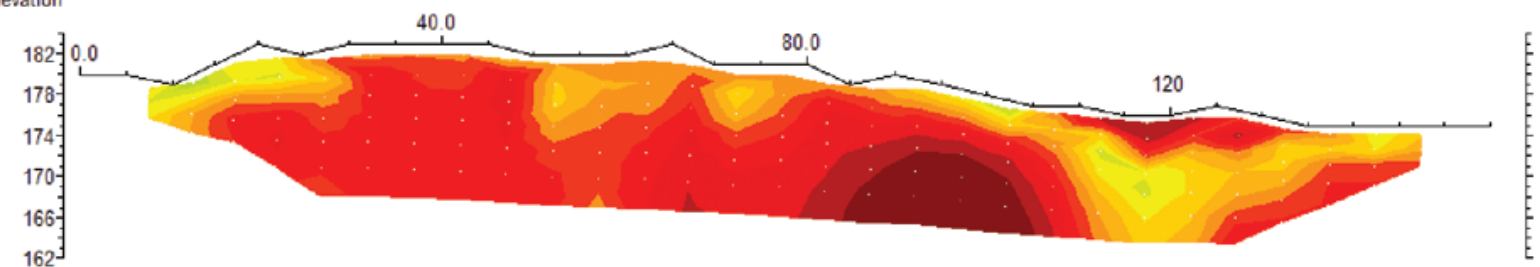

Model IP with topography L Linha 4

Iteration 3 RMS error $=20$.
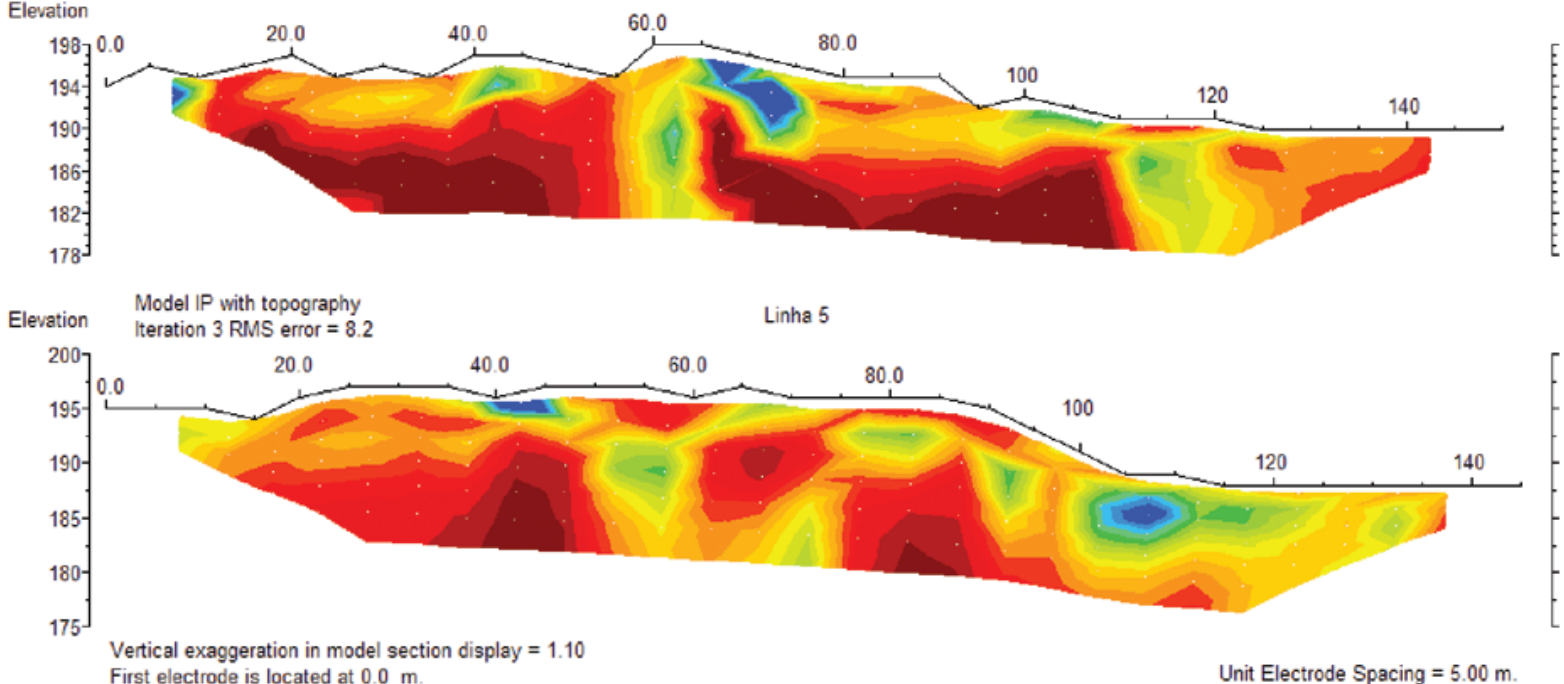

First electrode is located at $0.0 \mathrm{~m}$

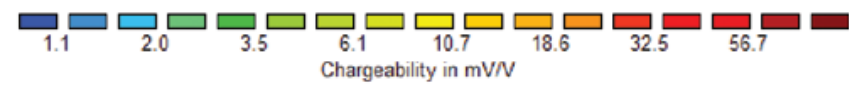

Figura 5 - Modelos de inversão de cargabilidade das linhas 1 a 5, com elevação em metros, exagero vertical de 1.1 x e correção topográfica. 

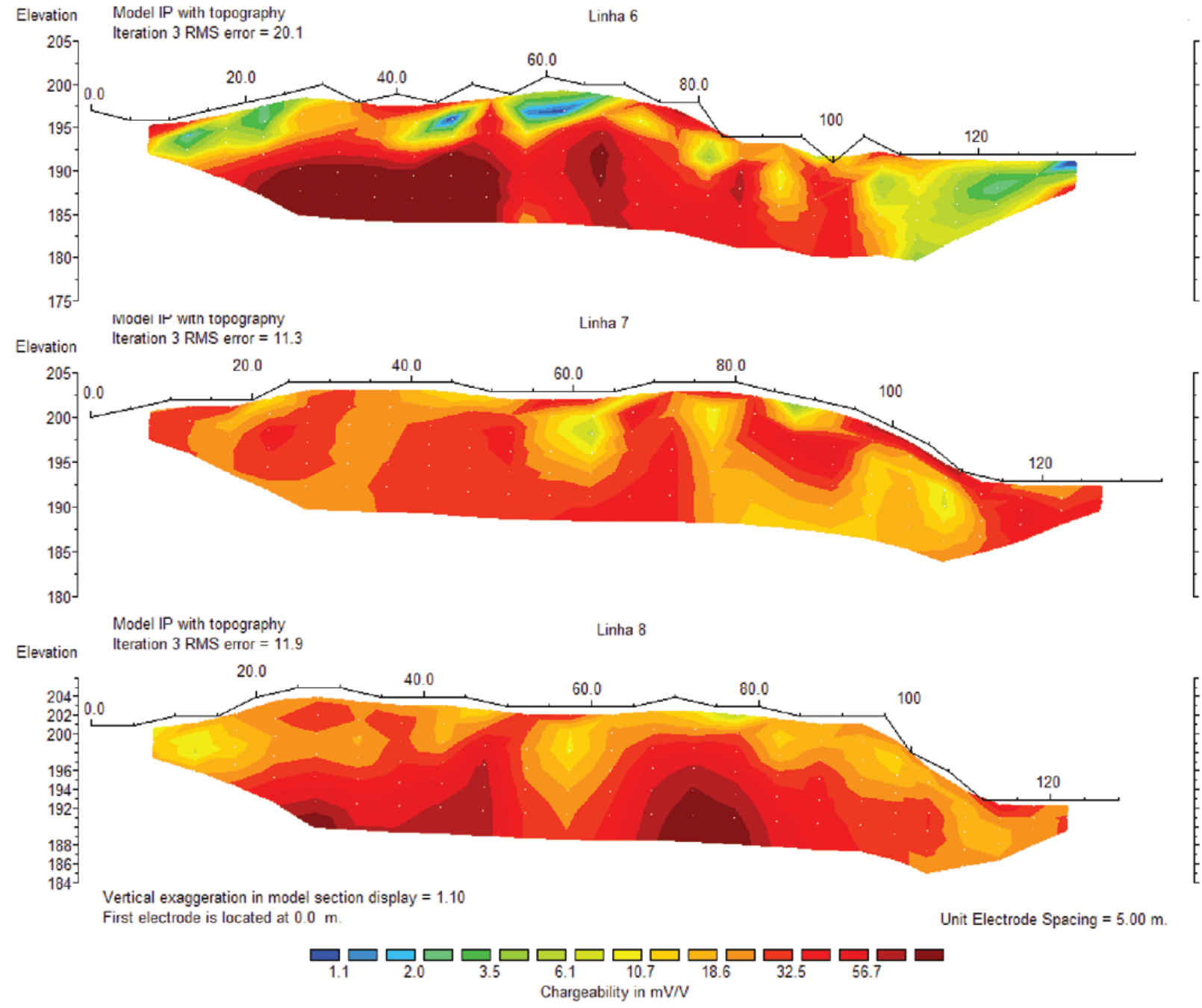

Figura 6 - Modelos de inversão de cargabilidade das linhas 6 a 8, com elevação em metros, exagero vertical de 1.1× e correção topográfica.

(2003) apresenta valores de cargabilidade da ordem de $31 \mathrm{mV} / \mathrm{N}$ para o intervalo de resíduos contidos em célula, com nível freático posicionado abaixo da célula de resíduos.

Em contrapartida, 0 trabalho de Moreira \& Braga (2009) apresenta baixos valores de cargabilidade em valas recentemente fechadas e nas valas mais antigas apresenta valores de cargabilidade altos, assentadas em solo argiloso, num contexto geológico que simula um aquífero suspenso.

Aparentemente existe uma relação entre intensidade de polarização e saturação do material analisado. Os altos valores de cargabilidade em resíduos enterrados num contexto de zona não saturada podem ser produto de polarização eletrônica, ou seja, elevada intensidade devido à presença de metais. Em contrapartida, os valores de baixa cargabilidade em resíduos dispostos em área com nível freático raso, ou seja, em zona saturada, refletem o fenômeno de polarização eletrolítica, de intensidade relativamente menor quando comparado ao fenômeno de polarização atribuído a materiais metálicos.

Os modelos de inversão apresentam anomalias verticais de baixa intensidade principalmente nas posições de $60 \mathrm{~m}$ e $120 \mathrm{~m}$. Os planos de fratura obtidos a partir de medidas estruturais revelam fraturas ortogonais às linhas de caminhamento elétrico, com mergulho próximo a $90^{\circ}$. Desta forma, é possível inferir à presença de fluidos provenientes da decomposição de matéria orgânica presente nos resíduos enterrados em planos de fraturas, principalmente nas posições $60 \mathrm{~m}$ e $120 \mathrm{~m}$, as quais devem representar zonas intensamente fraturadas.

Os resultados deste trabalho demonstram a aplicabilidade do 
método de Polarização Induzida em estudos de contaminação inorgânica em terrenos fraturados. Houve um contraste bastante claro entre zonas de fratura saturadas em água e possivelmente em chorume e a rocha metamórfica sotoposta.

\section{REFERÊNCIAS}

BITENCOURT MF. 1983. Metamorfitos da região de Caçapava do Sul, RS: Geologia e relações com o corpo granítico. In: Simpósio Sul-Brasileiro de Geologia. Porto Alegre: SBG, 1983. p. 37-48.

CETESB - COMPANHIA DE TECNOLOGIA DE SANEAMENTO AMBIENTAL. 2001. Manual de gerenciamento de áreas contaminadas. GTZ. 2 ed. São Paulo. 389 p.

CPRM - Serviço Geológico do Brasil. 2000. Programa Levantamentos Geológicos Básicos do Brasil. Cachoeira do Sul, Folha SH.22-Y-A. Estado do Rio de Grande do Sul. Escala 1:250.000. Organizado por Carlos Alfredo Porcher e Ricardo da Cunha Lopes. Brasília: CPRM.

CPRM - Serviço Geológico do Brasil. 2008. Mapa Geológico do Estado do Rio Grande do Sul. Escala 1: 750.000. Organizado por Wilson Wildner; Gilberto Emílio Ramgrab; Ricardo da Cunha Lopes; Carlos Moacyr Fontoura Iglesias - Porto Alegre: CPRM.

G00GLE EARTH. 2010. Versão 4.3 (beta). Europa Technologies - US Department of State Geographer.

IBGE - Instituto Brasileiro de Geografia e Estatística. 2002. Pesquisa Nacional de Saneamento Básico. Rio de Janeiro: Instituto Brasileiro de Geografia e Estatística. Disponível em: <www.ibge.gov.br>. Acesso em: 02 dez. 2009.

IBGE - Instituto Brasileiro de Geografia e Estatística. 2009. Pesquisa Nacional de Saneamento Básico. Rio de Janeiro: Instituto Brasileiro de Geografia e Estatística. Disponível em: <www.ibge.gov.br>. Acesso em: 02 dez. 2009.

JUCÁ JFT. 2003. Disposição Final dos resíduos sólidos urbanos no
Brasil. In: Congresso Brasileiro de Geotecnia Ambiental, 2003, Porto Alegre: REGEO, 2003. CD-ROM.

LAGO AL, ELIS VR \& GIACHETI HL. 2006. Aplicação integrada de métodos geofísicos em uma área de disposição de resíduos sólidos urbanos em Bauru-SP. Revista Brasileira de Geofísica, 24(3): 357-374.

LOKE MH \& BARKER RD. 1996. Rapid least-squares inversion of apparent resistivity pseudosections by a quasi-Newton method. Geophysical Prospecting, 44: 131-152.

LOWRIE W. 2007. Fundamentals of Geophysics. 2 ed. Cambridge University Press. $381 \mathrm{pp}$.

MILSOM J. 2003. Field Geophysics - The Geological Field Guide Series. 3 ed. London: Wiley, 249 pp.

MOREIRA CA \& BRAGA ACO. 2009. Decomposição de resíduos sólidos domiciliares e variações na resistividade e cargabilidade. Revista Brasileira de Geofísica, 27(3): 401-409.

MOURA HP \& MALAGUTTI F. 2003. Métodos de Eletrorresistividade e de Polarização Induzida aplicados na área de disposição de resíduos urbanos: Aterro Controlado de Rio Claro - SP. Geociências, 22(N. Esp.): 129-139.

OLIVEIRA S \& PASQUAL A. 2004. Avaliação de parâmetros indicadores de poluição por efluentes líquidos de um aterro sanitário. Revista de Engenharia Sanitária Ambiental, 9(3): 240-249.

PMC - Prefeitura Municipal de Caçapava do Sul. 1996. Antigo Lixão. Relatório Final. 42 pp.

POSSAMAI FP, VIANA E, SCHULZ HE, COSTA MM \& CASAGRANDE E. 2007. Lixões inativos na região carbonífera de Santa Catarina: análise dos riscos à saúde pública e ao meio ambiente. Ciência \& Saúde Coletiva, 12(1): 171-179.

TELFORD WM, GELDART LP \& SHERIFF RE. 1990. Applied Geophysics. 2 ed. Cambridge University Press, 770 pp.

\section{NOTAS SOBRE OS AUTORES}

Mônica Teixeira de Oliveira. Bacharel em Geofísica pela Universidade Federal do Pampa, UNIPAMPA/Campus Caçapava do Sul (RS). Áreas de interesse: Meio Ambiente, Mineração e Hidrogeologia.

César Augusto Moreira. Bacharel em Geologia pela Universidade Estadual Paulista, UNESP/Campus de Rio Claro-SP (2003). Doutorado em Geociências pela Universidade Estadual Paulista, UNESP/Campus de Rio Claro-SP (2009). Trabalhou como Professor Adjunto nos cursos de graduação em Geofísica e Geologia na Universidade Federal do Pampa, UNIPAMPA entre 2009 e 2011. Atualmente é Professor Assistente Doutor vinculado ao Departamento de Geologia Aplicada, IGCEUNESP/Rio Claro-SP. Áreas de interesse: Meio Ambiente, Mineração, Hidrogeologia e Geologia de Engenharia.

Aline Muriel da Cunha Menezes. Bacharel em Geofísica pela Universidade Federal do Pampa, UNIPAMPA/Campus Caçapava do Sul (RS). Atua como geofísica na Strataimage Geofísica, Rio de Janeiro. Áreas de atuação: geofísica aplicada, estratigrafia e análise de bacias. 